\title{
Investigations into Transition-Metal-Catalyzed Arene Trifluoromethylation Reactions
}

\author{
Yingda Ye, Melanie S. Sanford* \\ University of Michigan, Department of Chemistry, 930 North University Avenue, Ann Arbor, MI 48109, USA \\ Fax+1(734)6474865; E-mail: mssanfor@umich.edu \\ Received: 25.05.2012; Accepted after revision: 09.07.2012
}

\begin{abstract}
Trifluoromethyl-substituted arenes and heteroarenes are widely prevalent in pharmaceuticals and agrochemicals. As a result, the development of practical methods for the formation of aryl- $\mathrm{CF}_{3}$ bonds has become an active field of research. Over the past five years, transition-metal-catalyzed cross-coupling between aryl-X ( $\mathrm{X}=$ halide, organometallic, or $\mathrm{H}$ ) and various ' $\mathrm{CF}_{3}$ ' reagents has emerged as a particularly attractive approach to generating aryl$\mathrm{CF}_{3}$ bonds. Despite many recent advances in this area, current methods generally suffer from limitations such as poor generality, harsh reaction conditions, the requirement for stoichiometric quantities of metals, and/or the use of costly $\mathrm{CF}_{3}$ sources. This Account describes our recent efforts to address some of these challenges by: (1) developing aryltrifluoromethylation reactions involving high oxidation state Pd intermediates, (2) exploiting $\mathrm{AgCF}_{3}$ for $\mathrm{C}-\mathrm{H}$ trifluoromethylation, and (3) achieving $\mathrm{Cu}$-catalyzed trifluoromethylation with photogenerated $\mathrm{CF}_{3} \bullet$.
\end{abstract}

1 Introduction

2 Part 1. Aryltrifluoromethylation via High-Valent Palladium

3 Part 2. Aryltrifluoromethylation Using $\mathrm{AgCF}_{3}$

4 Part 3. Cu-Catalyzed Aryltrifluoromethylation with $\mathrm{CF}_{3}$ •

5 Outlook

Key words: trifluoromethylation, cross-coupling, palladium, silver, photocatalysis

\section{$1 \quad$ Introduction}

Trifluoromethylarenes and heteroarenes are increasingly important structural features of pharmaceuticals and agrochemicals. The incorporation of a trifluoromethyl group into an organic molecule can dramatically impact a variety of properties, including metabolic stability, lipophilicity, and bioavailability. ${ }^{1}$ Despite the significance of this functional group in medicinal chemistry, mild, efficient, and functional-group tolerant methods for the formation of aryl/heteroaryl- $\mathrm{CF}_{3}$ linkages have been limited until very recently. ${ }^{1 \mathrm{f}, 2}$

On the industrial scale, trifluoromethylated arenes are mainly produced by the Swarts reaction, which was developed in $1892 .{ }^{3}$ This transformation involves a two-step conversion of toluene derivatives into benzotrifluorides through radical chlorination followed by treatment with an inorganic fluoride (e.g., $\mathrm{SbF}_{5}$ ) or anhydrous hydrogen fluoride (Scheme 1). ${ }^{3}$ The requirement for reactive fluori-

SYNLETT 2012, 23, 2005-2013

Advanced online publication: 08.08 .2012

DOI: 10.1055/s-0032-1316988; Art ID: ST-2012-A0456-A

(C) Georg Thieme Verlag Stuttgart · New York nating reagents and high temperatures render this strategy incompatible with many common functional groups. Thus, the development of mild and flexible alternative methods for the installation of $\mathrm{CF}_{3}$ groups, particularly at late stages in the synthesis of complex molecules, is highly desirable.

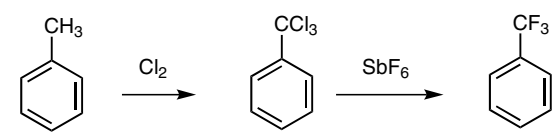

Scheme 1

This Account describes our efforts in methods development and mechanistic investigations of transition-metalmediated aromatic trifluoromethylation reactions. When we initiated our work in this area in 2009, three groups had just reported exciting advances in $\mathrm{Pd}$ - and $\mathrm{Cu}$-promoted arene trifluoromethylation reactions. For example, in 2006, Grushin demonstrated that (Xantphos) $\mathrm{Pd}(\mathrm{Ph})\left(\mathrm{CF}_{3}\right)$ undergoes stoichiometric $\mathrm{Ph}-\mathrm{CF}_{3}$ bond-forming reductive elimination to release trifluorotoluene under mild conditions $\left(80^{\circ} \mathrm{C}, 3 \mathrm{~h}\right.$; Scheme 2$){ }^{4}{ }^{4}$ This was the first reported example of selective aryl- $\mathrm{CF}_{3}$ coupling from a $\mathrm{Pd}$ center. The properties of the Xantphos ligand (particularly its large bite angle) were hypothesized to play an important role in this novel transformation.

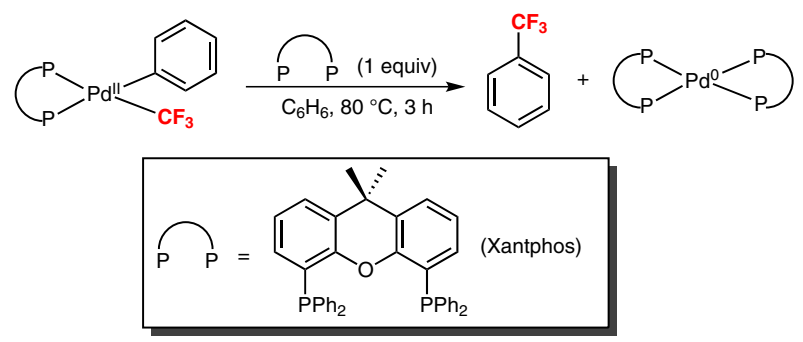

Scheme 2

A major advance in the area of $\mathrm{Cu}$-promoted trifluoromethylation was made in 2008, when Vicic reported the first example of an isolable, crystallographically characterized $\mathrm{Cu}^{\mathrm{I}}-\mathrm{CF}_{3}$ complex (Scheme 3). ${ }^{5}$ This complex, which is supported by an N-heterocyclic carbene ligand, was shown to react with aryl iodides under mild conditions $\left(25^{\circ} \mathrm{C}, 112 \mathrm{~h}\right)$ to liberate trifluoromethylated products (Scheme 3). While related Cu-mediated trifluoromethylations were known prior to this report, ${ }^{1 f}$ 
these previous systems generally involved ill-defined ' $\mathrm{Cu}-\mathrm{CF}_{3}$ ' intermediates.<smiles>CC(C)N1CCN(C(C)C)C(C2N(C(C)C)CCN2C(C)C)C1</smiles>

Scheme 3

A final significant advance that occurred just prior to our entry into the field was a 2009 report by Amii. ${ }^{6}$ This work demonstrated the first copper-catalyzed trifluoromethylation of aryl iodides. As shown in Scheme 4, 1,10-phenanthroline (phen) was used as a supporting ligand for $\mathrm{Cu}$ in conjunction with $\mathrm{TMSCF}_{3}$ as the $\mathrm{CF}_{3}$ source. A variety of electron-deficient aryl iodides underwent trifluoromethylation under these conditions.

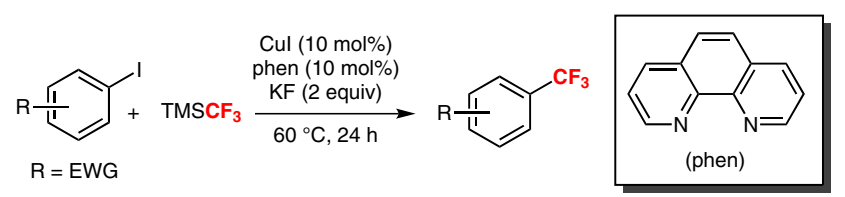

Scheme 4

Our goal was to build on these exciting advances by developing new mechanistic pathways for metal-mediated aryl $-\mathrm{CF}_{3}$ coupling reactions. Over the last three years, we have pursued three different strategies to achieve this goal (Scheme 5). Strategy 1 involves aryltrifluoromethylation via reductive elimination from high-valent $\mathrm{Pd}^{\mathrm{IV}}(\mathrm{ar}-$ $\mathrm{yl})\left(\mathrm{CF}_{3}\right)$ intermediates. Strategy 2 involves exploiting
$\mathrm{AgCF}_{3}$ intermediates to achieve aryl- $\mathrm{CF}_{3}$ bond formation. Finally, strategy 3 involves the trifluoromethylation of aryl- $\mathrm{Cu}$ intermediates with $\mathrm{CF}_{3} \cdot$. All three of these approaches are described in detail below.

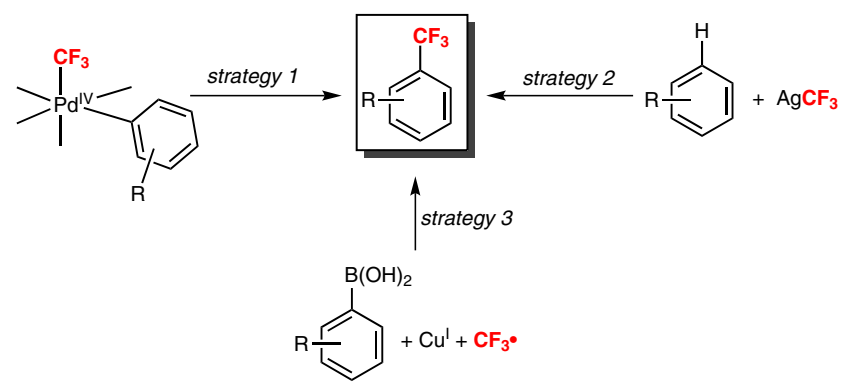

Scheme 5 Three different strategies used in the Sanford group for aryl- $\mathrm{CF}_{3}$ coupling

\section{Part 1. Aryltrifluoromethylation via High- Valent Palladium}

Historically, it has proven challenging to achieve aryl$\mathrm{CF}_{3}$ bond-forming reductive elimination from $\mathrm{Pd}^{\mathrm{II}}$ centers. Only two high-yielding examples of this transformation have been reported in the literature, and both involve the use of specialized phosphine ligands to induce the desired reactivity. As described above, Grushin reported $\mathrm{Ph}-\mathrm{CF}_{3}$ coupling from (Xantphos) $\mathrm{Pd}{ }^{\mathrm{II}}(\mathrm{Ph})\left(\mathrm{CF}_{3}\right)$ in 2006 (Scheme 2). ${ }^{4 a}$ More recently, Buchwald has shown that (Brettphos) $\mathrm{Pd}^{\mathrm{II}}(\operatorname{aryl})\left(\mathrm{CF}_{3}\right) \quad\left\{\right.$ Brettphos $=\operatorname{dicyclohexyl}\left(2^{\prime}-\right.$ isopropyl-3,6-dimethoxy-4',6'-dipropyl-[1, 1'-biphenyl]2-yl)phosphine $\}$ also undergoes aryl- $\mathrm{CF}_{3}$ bond-forming reductive elimination under mild conditions $\left(80^{\circ} \mathrm{C}, \sim 30\right.$ $\min ) .^{7}$

\section{Biographical Sketches}

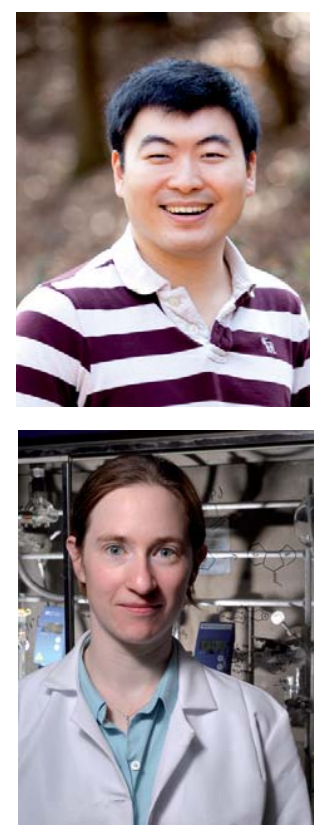

Yingda Ye was born in Beijing, China in 1983. He received his B.E. degree in Computer Science from Beijing University of Technology in 2006. He then studied computer-aided

Melanie Sanford was born in New Bedford, MA, USA in 1975. She received B.Sc. and M.Sc. degrees in chemistry from Yale University in 1996 and a Ph.D. in drug design and pharmaceutical chemistry and obtained his M.Sc. at Tianjin University with Professor Kang Zhao in 2008. He has been working toward his Ph.D. at the University of Michigan

chemistry from California Institute of Technology in 2001. After post-doctoral studies at Princeton University, she joined the faculty at the University of Michigan with Professor Melanie Sanford since 2009, where he is focusing on transitionmetal-catalyzed aromatic trifluoromethylation reactions.

in 2003, where she is currently the Moses Gomberg Collegiate Professor as well as an Arthur F. Thurnau Professor of Chemistry. 
Our group aimed to achieve aryl- $\mathrm{CF}_{3}$ coupling from $\mathrm{Pd}$ using a different, complementary approach. Rather than modifying the ligands at $\mathrm{Pd}^{\mathrm{II}}$, we sought to access the desired reactivity by changing the oxidation state of the $\mathrm{Pd}$ center from $\mathrm{Pd}^{\mathrm{II}}$ to $\mathrm{Pd}^{\mathrm{IV}}$. This idea was predicated on the fact that $\mathrm{Pd}^{\mathrm{IV}}$ complexes are well known to undergo other reductive elimination reactions (e.g., $\mathrm{C}-\mathrm{F}, \mathrm{C}-\mathrm{Cl}, \mathrm{C}-\mathrm{I}, \mathrm{C}-$ $\mathrm{N}, \mathrm{C}-\mathrm{O}$ ) that have proven challenging at $\mathrm{Pd}^{\mathrm{II}}$ centers. ${ }^{8}$ To probe the viability of this strategy, we synthesized and studied the reactivity of $\mathrm{Pd}^{\mathrm{IV}}(\operatorname{aryl})\left(\mathrm{CF}_{3}\right)$ intermediates. Two different synthetic routes were used to access these compounds: the $2 e^{-}$oxidation of pre-formed Pd (ar$\mathrm{yl}\left(\mathrm{CF}_{3}\right)$ complexes (Scheme 6a) and the oxidation of $\mathrm{Pd}^{\mathrm{II}}\left(\right.$ aryl) complexes with $\mathrm{CF}_{3}{ }^{+}$reagents (Scheme 6b).

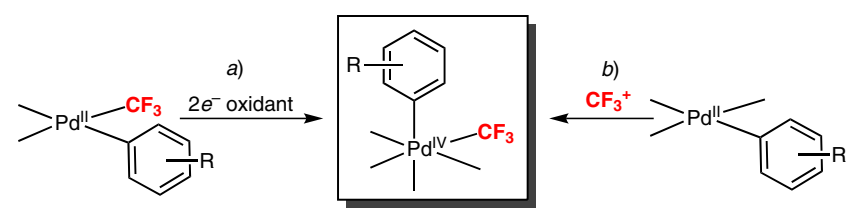

Scheme 6 Two synthetic routes to $\mathrm{Pd}^{\mathrm{IV}}(\operatorname{aryl})\left(\mathrm{CF}_{3}\right)$ complexes

We initially pursued the synthesis of $\mathrm{Pd}^{\mathrm{IV}}(\operatorname{aryl})\left(\mathrm{CF}_{3}\right)$ complexes via the $2 e^{-}$oxidation of $(\mathrm{N} \sim \mathrm{N}) \mathrm{Pd}^{\mathrm{II}}(\operatorname{aryl})\left(\mathrm{CF}_{3}\right)(\mathbf{1}){ }^{9}$ 4,4'-Di-tert-butyl-2,2'-bipyridine (dtbpy) was selected as the $\mathrm{N} \sim \mathrm{N}$ ligand, since its rigid, bidentate structure is known to stabilize $\mathrm{Pd}^{\mathrm{IV}}$ complexes. ${ }^{10}$ As shown in Scheme 7, $N$-fluoro-2,4,6-trimethyl-pyridinium triflate (NFTPT) proved to be particularly effective for the oxidation of $\mathbf{1}$, yielding 2 in 53\% isolated yield. This product was fully characterized by NMR spectroscopy and X-ray crystallography.

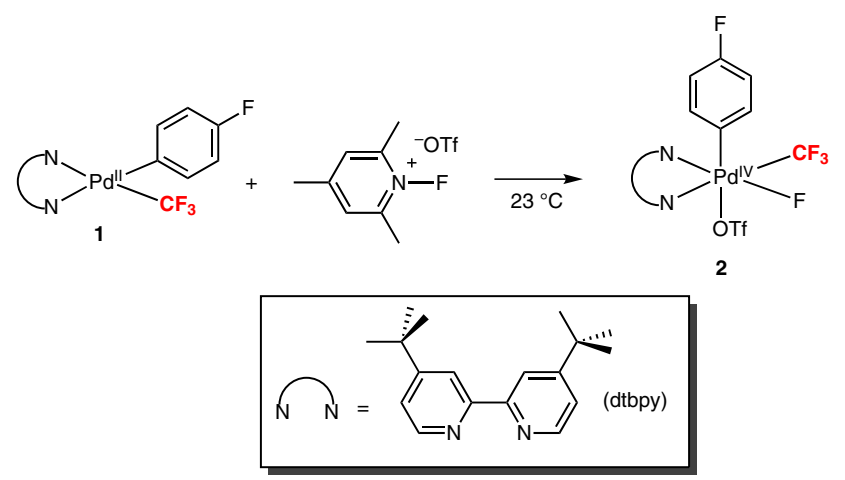

Scheme 7

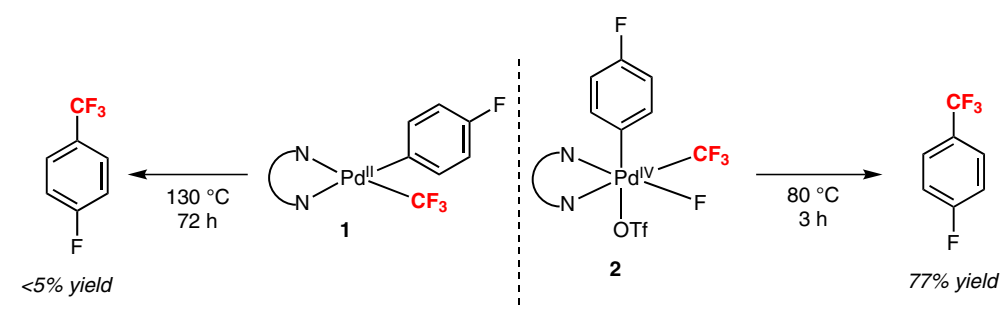

The availability of pure samples of $\mathbf{1}$ and $\mathbf{2}$ enabled a direct comparison of aryl- $\mathrm{CF}_{3}$ bond formation from dtbpyligated $\mathrm{Pd}^{\mathrm{II}}$ versus $\mathrm{Pd}^{\mathrm{IV}}$ centers. As shown in Scheme 8, $\mathrm{Pd}^{\mathrm{II}}$ complex 1 was inert towards thermal reductive elimination, affording $<5 \%$ yield of $p-\mathrm{F}-\mathrm{Ph}-\mathrm{CF}_{3}$ even after 72 $\mathrm{h}$ at $130{ }^{\circ} \mathrm{C}$ (mass balance was predominantly recovered starting material). In marked contrast, the analogous $\mathrm{Pd}^{\mathrm{IV}}$ complex underwent high yielding aryl- $\mathrm{CF}_{3}$ bond-forming reductive elimination over $3 \mathrm{~h}$ at just $80^{\circ} \mathrm{C}$ (Scheme 8). Notably, products derived from competing aryl-F or arylOTf coupling were not observed from $\mathbf{2}$, presumably due to the low reactivity of these ligands towards reductive elimination. ${ }^{2 a, 10 a, b, 11}$ Overall, the results given in Scheme 8 confirmed our original hypothesis that aryl- $\mathrm{CF}_{3}$ coupling can be accelerated by oxidation of a Pd center from $\mathrm{Pd}^{\mathrm{II}}$ to $\mathrm{Pd}^{\mathrm{IV}}$.

Experimental and computational mechanistic studies indicate that aryl- $\mathrm{CF}_{3}$ coupling from 2 proceeds via pre-equilibrium triflate dissociation (step $i$ ) followed by aryl- $\mathrm{CF}_{3}$ bond-formation from cationic intermediate 3 (step ii, Scheme 9). These results led us to propose that replacing the dtbpy ligand with $N, N, N^{\prime}, N^{\prime}$-tetramethylethylenediamine (tmeda) would result in an acceleration of this $\mathrm{C}-\mathrm{C}$ bond-forming event. Importantly, literature precedent has shown that the use of more flexible tmeda increases the rate of $\mathrm{C}-\mathrm{C}$ coupling from the related $\mathrm{Pd}^{\mathrm{IV}}$ complexes $(\mathrm{N} \sim \mathrm{N}) \mathrm{Pd}^{\mathrm{IV}}\left(\mathrm{CH}_{3}\right)_{2}(\mathrm{Ph})(\mathrm{I}) \quad\left(\mathrm{N} \sim \mathrm{N}=\right.$ bpy versus tmeda). ${ }^{12}$ DFT calculations of analogues of $\mathbf{2}$ were consistent with this hypothesis, predicting that both triflate dissociation and aryl- $-\mathrm{CF}_{3}$ coupling would be faster with tmeda. Experimental studies confirmed that the $\mathrm{Pd}^{\mathrm{IV}}$ tmeda complex 5 is significantly more reactive than $\mathbf{2}$, as substitution of tmeda for dtbpy enables aryl- $\mathrm{CF}_{3}$ coupling to proceed at room temperature rather than $80{ }^{\circ} \mathrm{C}$ (Scheme 9)!

This work provides the basis for the development of many different types of $\mathrm{Pd}^{\mathrm{II} / \mathrm{IV}}$-catalyzed aryl- $\mathrm{CF}_{3}$ cross-coupling reactions. A potential catalytic cycle for such transformations is outlined in Scheme 10. Step $i$ involves formation of a Pd ${ }^{\mathrm{II}}$ (aryl) complex, which could occur, for example, by $\mathrm{C}-\mathrm{H}$ activation $(\mathrm{X}=\mathrm{H})$ or transmetalation $\left(\mathrm{X}=\mathrm{B}, \mathrm{Sn}, \mathrm{Si}\right.$ ). Subsequent reaction with $\mathrm{TMSCF}_{3}$ (step ii) would yield $\mathrm{Pd}^{\mathrm{II}}(\operatorname{aryl})\left(\mathrm{CF}_{3}\right)(\mathbf{A})$. Two-electron oxidation of $\mathbf{A}$ (step iii) followed by aryl- $\mathrm{CF}_{3}$ bond-forming reductive elimination (step $i v$ ) would then furnish the trifluoromethylated product and regenerate the catalyst.

This approach is already being adopted to achieve synthetically useful trifluoromethylation reactions. For example, a recent report by Liu and co-workers exploited

\section{Scheme 8}



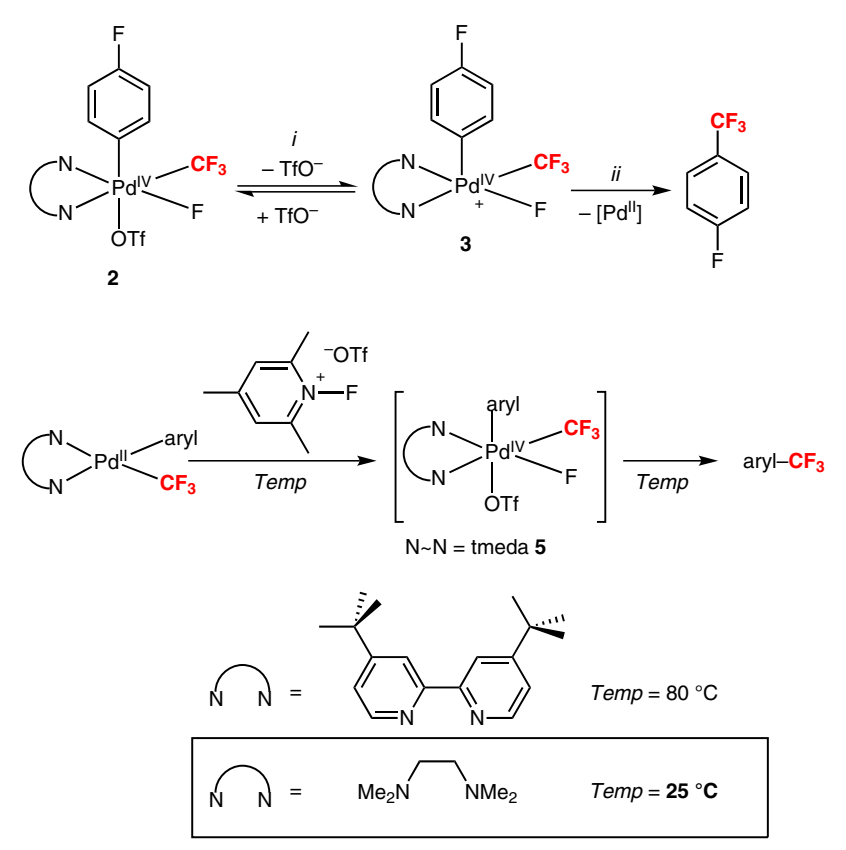

Scheme 9

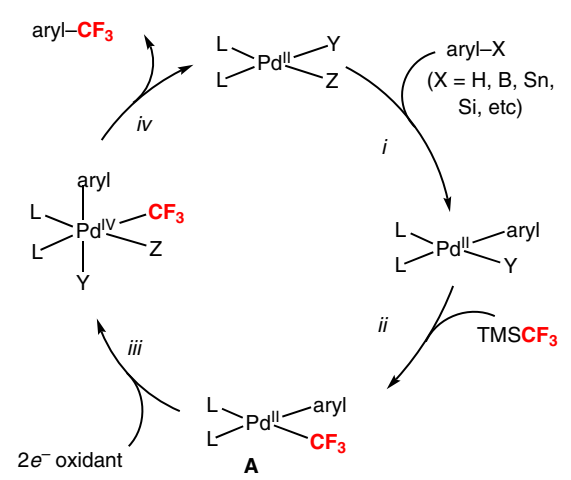

Scheme 10 General catalytic cycle for Pd-catalyzed oxidative trifluoromethylation with $\mathrm{TMSCF}_{3}$

this strategy in the $\mathrm{Pd}$-catalyzed $\mathrm{C}-\mathrm{H}$ trifluoromethylation of indoles (Scheme 11). ${ }^{13}$ While detailed mechanistic investigations of this transformation have not yet been conducted, the combination of aryl-H (indole), $\mathrm{TMSCF}_{3}$, and an oxidant $\left[\mathrm{PhI}(\mathrm{OAc})_{2}\right]$ was proposed to react via a cycle very similar to that depicted in Scheme 10. A related pathway has also been proposed for the Pd-catalyzed aryltrifluoromethylation of alkenes. ${ }^{14}$ Numerous analogous transformations can be envisioned, and we anticipate that this approach could find widespread utility for Pd-catalyzed trifluoromethylation sequences.<smiles>Cc1cc2ccccc2n1[N+](=O)[O-]</smiles>
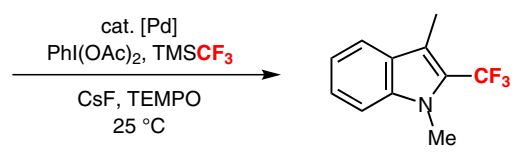

Scheme 11

Our second strategy for generating $\mathrm{Pd}^{\mathrm{IV}}(\operatorname{aryl})\left(\mathrm{CF}_{3}\right)$ intermediates is via the reaction of $\mathrm{Pd}^{\mathrm{II}}($ aryl $)$ complexes with
$\mathrm{CF}_{3}{ }^{+}$reagents (Scheme 12). Here the $\mathrm{CF}_{3}{ }^{+}$plays two roles. First, it serves to oxidize the $\mathrm{Pd}^{\mathrm{II}}$ to $\mathrm{Pd}^{\mathrm{IV}}$ and, second, it serves as the source of $\mathrm{CF}_{3}$ in the product.

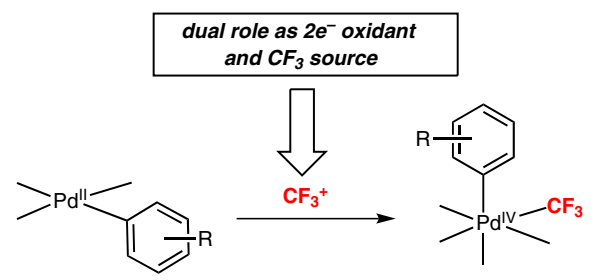

Scheme 12

We initially examined the feasibility of using this transformation in the context of the cyclopalladated dimer $\left[(\mathrm{bzq}) \mathrm{Pd}^{\mathrm{II}}(\mathrm{OAc})\right]_{2}(6)$. This complex was selected for study for two reasons. First, it contains a rigid cyclometalated $\sigma$-aryl ligand, which should stabilize high-valent $\mathrm{Pd}$ oxidation products. ${ }^{15}$ Second, it is believed to be a catalytically relevant intermediate in $\mathrm{C}-\mathrm{H}$ functionalization reactions of benzo[h]quinoline. ${ }^{16}$ As such, studies of its reactivity could potentially be directly applicable to the development of catalytic ligand-directed $\mathrm{C}-\mathrm{H}$ trifluoromethylation reactions.

The reaction of 6 with $\mathrm{CF}_{3}{ }^{+}$reagents 7-9 in AcOH afforded the $\mathrm{Pd}^{\mathrm{IV}}$ complex 10 (Scheme 13). ${ }^{17}$ This complex was fully characterized by NMR spectroscopy and by X-ray crystallography.
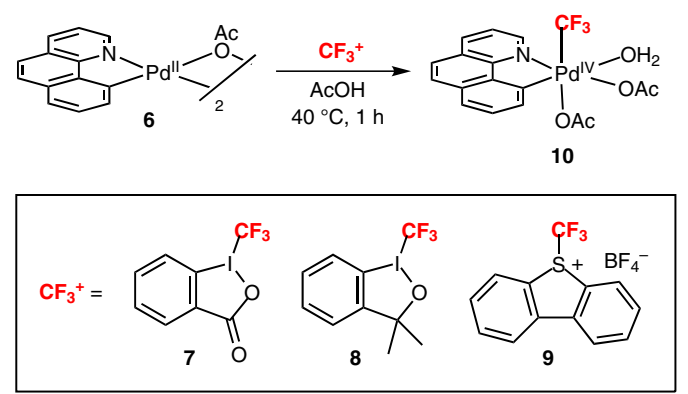

Scheme 13

Complex 10 was stable at room temperature, but it decomposed at $60^{\circ} \mathrm{C}$ to form the aryl- $\mathrm{CF}_{3}$ coupled product $\mathbf{1 1}$ (Scheme 14). However, under all of the conditions examined, the formation of $\mathbf{1 1}$ was sluggish, showed an induction period, and proceeded in only modest yield $(56 \%$ in $\mathrm{AcOH}$ ), with poor mass balance. While we have not yet been able to completely explain these results, we have identified additives that ameliorate many of these issues. In particular, reactions conducted in the presence of Brønsted acids (e.g., trifluoroacetic acid) or Lewis acids [e.g., $\left.\mathrm{Yb}(\mathrm{OTf})_{3}\right]$ were faster, occurred with minimal induction periods, and proceeded in significantly higher yields than those without these additives (Scheme 14).

The lessons learned from these stoichiometric studies have proven to be highly relevant to Pd-catalyzed ligand- 


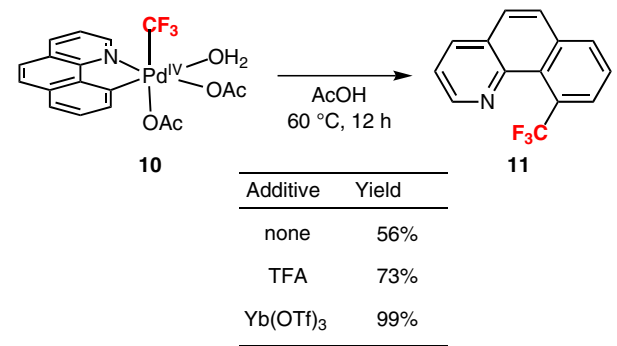

Scheme 14

directed $\mathrm{C}-\mathrm{H}$ trifluoromethylation reactions. In an elegant recent paper, $\mathrm{Yu}$ and co-workers achieved the Pd-catalyzed $\mathrm{C}-\mathrm{H}$ trifluoromethylation of a variety of aromatic substrates using 9 as the $\mathrm{CF}_{3}{ }^{+}$source (Scheme 15). The optimal conditions for these transformations [using a chlorinated solvent in the presence of a Brønsted acid (TFA) and a Lewis acid $\left.\left(\mathrm{Cu}(\mathrm{OAc})_{2}\right)\right]$ are remarkably similar to those identified in our stoichiometric reactions with $\mathbf{6}$ and $11 .^{18}$
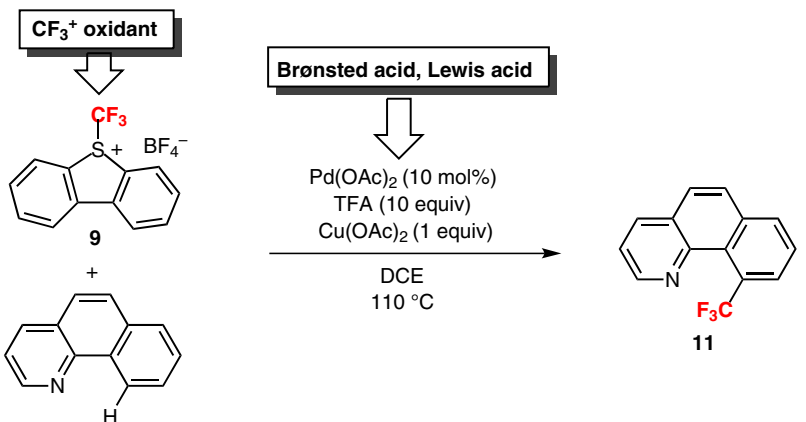

\section{Scheme 15}

This suggested the possibility that $\mathrm{Pd}^{\mathrm{IV}}$ complex 10 might be an intermediate under Yu's catalytic reactions. Consistent with this proposal, the use of $\mathbf{1 0}$ as catalyst provided nearly identical yield to that obtained with $\mathrm{Pd}(\mathrm{OAc})_{2}$. Furthermore, analysis of the initial rates with $\mathrm{Pd}(\mathrm{OAc})_{2}$ versus 10 showed that the $\mathrm{Pd}^{\mathrm{IV}}$ complex is a kinetically competent catalyst for $\mathrm{C}-\mathrm{H}$ trifluoromethylation. ${ }^{17}$

Overall, these studies demonstrate the viability of catalytic cycles such as that depicted in Scheme 16 for $\mathrm{Pd}^{\mathrm{II} / \mathrm{IV}}$-catalyzed trifluoromethylation. This cycle involves initial generation of $\mathrm{Pd}^{\mathrm{II}}$ (aryl) intermediate $\mathbf{B}$ via $\mathrm{C}-\mathrm{H}$ activation or transmetalation ( $\operatorname{step} i$ ). Oxidation of $\mathbf{B}$ with $\mathrm{CF}_{3}{ }^{+}$(step ii) and subsequent $\mathrm{C}-\mathrm{CF}_{3}$ coupling (step iii) then releases the trifluoromethylated product. We anticipate that this pathway could prove broadly useful for a number of different Pd-catalyzed transformations for introducing $\mathrm{CF}_{3}$ groups into organic molecules.

\section{$3 \quad$ Part 2. Aryltrifluoromethylation Using $\mathrm{AgCF}_{3}$}

Our second approach to uncovering new pathways for arene trifluoromethylation has been to explore metal catalysts beyond $\mathrm{Pd}$ and $\mathrm{Cu}$. Our initial efforts in this area fo-

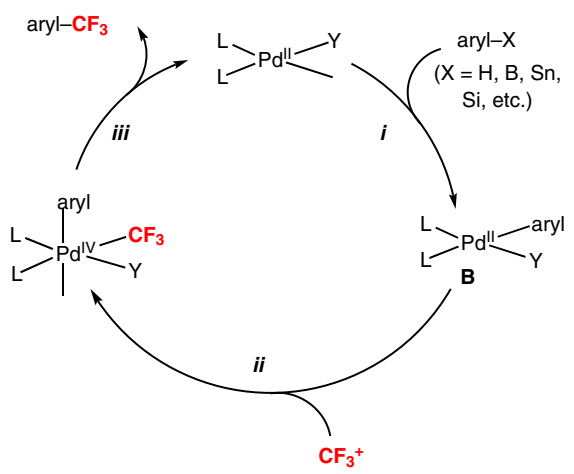

Scheme 16 General catalytic cycle for Pd-catalyzed oxidative trifluoromethylation with $\mathrm{CF}_{3}^{+}$reagents

cused on $\mathrm{Ag}$ for three reasons. First, $\mathrm{Ag}^{\mathrm{I}}$ has the same electronic configuration as $\mathrm{Cu}^{\mathrm{I}}$, which suggests the possibility of similar reactivity. Second, $\mathrm{Ag}^{\mathrm{I}}$ salts have recently been used as catalysts for related organometallic reactions, including the fluorination of arylstannanes with $\mathrm{F}^{+}$ reagents. ${ }^{19}$ These examples suggest the possibility that organometallic Ag complexes can participate in aryl-X bond-forming transformations. Third, $\mathrm{AgCF}_{3}$ is readily synthetically accessible (although its reactivity with organic substrates had not previously been explored extensively). ${ }^{20}$

We first examined the reaction between $\mathrm{AgCF}_{3}$ and iodobenzene. PhI was selected as a substrate because it is known to react with $\mathrm{CuCF}_{3}$ complexes to generate trifluorotoluene (Scheme 17a). If Very surprisingly, treatment of $\mathrm{AgCF}_{3}$ with $\mathrm{PhI}$ did not yield the expected cross-coupled product $\mathrm{PhCF}_{3}$. Instead, this reaction afforded a mixture of three isomeric $\mathrm{C}-\mathrm{H}$ trifluoromethylation products (iodobenzotrifluorides) (Scheme 17b). ${ }^{21}$ This is a particularly exciting result because it shows that moving to a different metal (from $\mathrm{Cu}$ to $\mathrm{Ag}$ ) results in completely complementary reactivity.

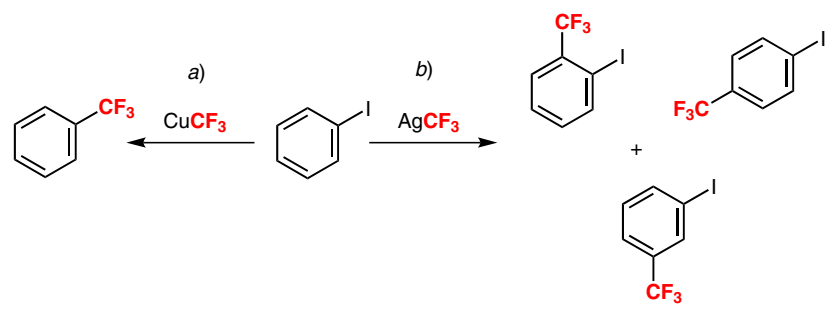

Scheme 17

Optimization of this transformation led to a new Ag-promoted trifluoromethylation reaction that is applicable to a variety of substrates. ${ }^{18}$ As summarized in Scheme 18, reactions of electron-rich aromatic and heteroaromatic compounds afforded particularly high yields. Somewhat lower yields were obtained with electron-deficient aromatics. In substrates containing more than one type of aromatic C$\mathrm{H}$ bond, mixtures of isomeric trifluoromethylated products were generally obtained. This feature could prove valuable to medicinal chemists because it enables the transformation of a single lead molecule into a variety of 


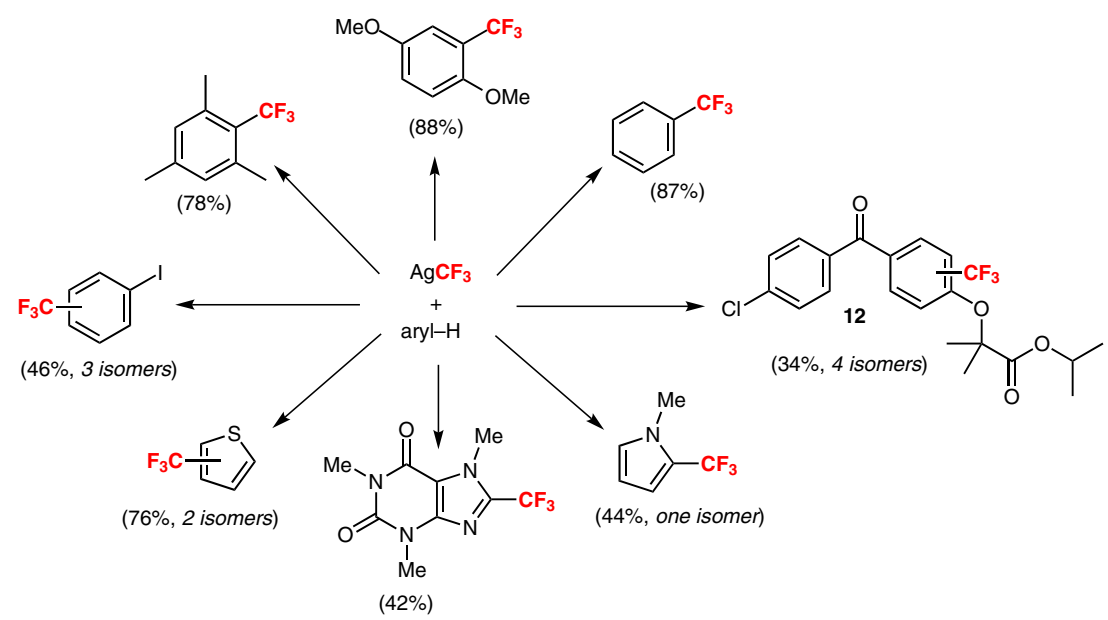

Scheme $18 \mathrm{C}-\mathrm{H}$ trifluoromethylation reactions with $\mathrm{AgCF}_{3}$

different trifluoromethylated analogues in a single operation. This is exemplified in the formation of $\mathbf{1 2}$ as a mixture of four isomers from the trifluoromethylation of Tricor (a commercial cholesterol-lowering drug).

While detailed mechanistic studies have not yet been conducted, several pieces of evidence implicate a pathway involving homolysis of the $\mathrm{Ag}-\mathrm{CF}_{3}$ bond to generate $\mathrm{Ag}^{0}$ and $\mathrm{CF}_{3} \cdot$ followed by $\mathrm{C}-\mathrm{H}$ functionalization via radical aromatic substitution. First, a Ag mirror is observed at the bottom of the flask at the end of these reactions, which is indicative of the reduction of $\mathrm{Ag}^{\mathrm{I}}$ to $\mathrm{Ag}^{0}$. Additionally, the high reactivity with electron-rich aromatics is consistent with the intermediacy of an electrophilic $\mathrm{CF}_{3}$ radical. ${ }^{22} \mathrm{Fi}-$ nally, the addition of one equivalent of 2,2,6,6-(tetramethylpiperidin-1-yl)oxyl (TEMPO) to this transformation resulted in a dramatic reduction of the yield, suggesting the possibility that this additive is trapping the key $\mathrm{CF}_{3}$. intermediate. $^{12}$

Overall these efforts demonstrate the viability of $\mathrm{Ag}$ as a promoter for $\mathrm{C}-\mathrm{H}$ trifluoromethylation. The $\mathrm{AgCF}_{3}-\mathrm{me}-$ diated transformations proceed under mild conditions and are complementary to analogous reactions of $\mathrm{CuCF}_{3}$. In addition, this work adds to a growing body of evidence suggesting that $\mathrm{CF}_{3} \bullet$ is a potent reagent for synthetically useful $\mathrm{C}-\mathrm{H}$ trifluoromethylation reactions. For example, Baran and MacMillan have recently demonstrated the $\mathrm{C}-$ $\mathrm{H}$ trifluoromethylation of complex molecules with $\mathrm{CF}_{3} \bullet$ generated from either $\mathrm{NaSO}_{2} \mathrm{CF}_{3} / t-\mathrm{BuOOH}$ (Baran) ${ }^{23}$ or $\mathrm{CF}_{3} \mathrm{SO}_{2} \mathrm{Cl} / \mathrm{Ru}$ (phen) ${ }_{3}{ }^{2+} /$ visible light (MacMillan). ${ }^{24,25}$ All of these transformations serve as valuable methods for the trifluoromethylation of aromatic/heteroaromatic substrates under mild and functional-group-tolerant conditions.

\section{Part 3. Cu-Catalyzed Aryltrifluoromethyl- ation with $\mathrm{CF}_{3}$ •}

A third objective of our efforts in this area has been to identify new pathways for $\mathrm{Cu}$-catalyzed boronic acid tri- fluoromethylation. Prior work had demonstrated that this transformation can be achieved via transfer of nucleophilic $\mathrm{CF}_{3}^{-}$[derived from, for example, $\mathrm{TMSCF}_{3}$ or $\left.\mathrm{K}(\mathrm{MeO})_{3} \mathrm{~B}\left(\mathrm{CF}_{3}\right)\right]^{26,27}$ or electrophilic $\mathrm{CF}_{3}{ }^{+}$(derived, for example, from 7-9) ${ }^{28}$ to the $\mathrm{Cu}$ catalyst (Scheme 19). These two approaches are limited by the relatively high cost of some $\mathrm{CF}_{3}{ }^{-} / \mathrm{CF}_{3}{ }^{+}$reagents, limited functional group tolerance in the presence of these highly nucleophilic/electrophilic reagents, and the requirement for high temperatures in some systems. We reasoned that these limitations could potentially be addressed by accessing an alternative mechanistic manifold in which $\mathrm{CF}_{3}$ transfer to the metal center occurs via $\mathrm{CF}_{3} \bullet$ (Scheme 19). As discussed above in Part $2, \mathrm{CF}_{3} \cdot$ can effect $\mathrm{C}-\mathrm{H}$ trifluoromethylation via radical aromatic substitution. Thus, a key challenge for this approach is to identify a system in which reaction of $\mathrm{CF}_{3} \cdot$ with the metal catalyst is faster than competing uncatalyzed $\mathrm{C}-\mathrm{H}$ trifluoromethylation. We selected $\mathrm{Cu}$-based catalysts based on the fact that they are susceptible to rapid $1 e^{-}$oxidation reactions.

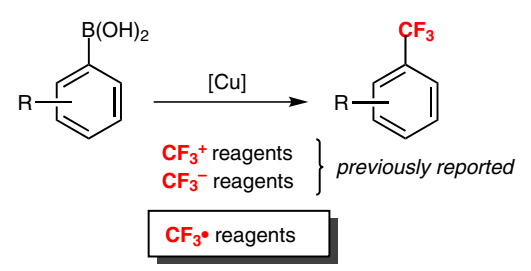

Scheme 19

Our proposed approach to $\mathrm{Cu}$-catalyzed trifluoromethylation requires a mild and readily available source of $\mathrm{CF}_{3}{ }^{\circ}$. We were inspired by several recent reports by MacMillan that used $\mathrm{CF}_{3} \mathrm{I}$ as a precursor to $\mathrm{CF}_{3}$ in the presence of visible light and a photocatalyst. ${ }^{29}$ As such, our initial studies focused on the $\mathrm{Cu}$-catalyzed trifluoromethylation of boronic acid derivatives with $\mathrm{CF}_{3} \mathrm{I}$ in the presence of $\mathrm{Ru}(\text { bpy })_{3}{ }^{2+}$ (Scheme 20). 


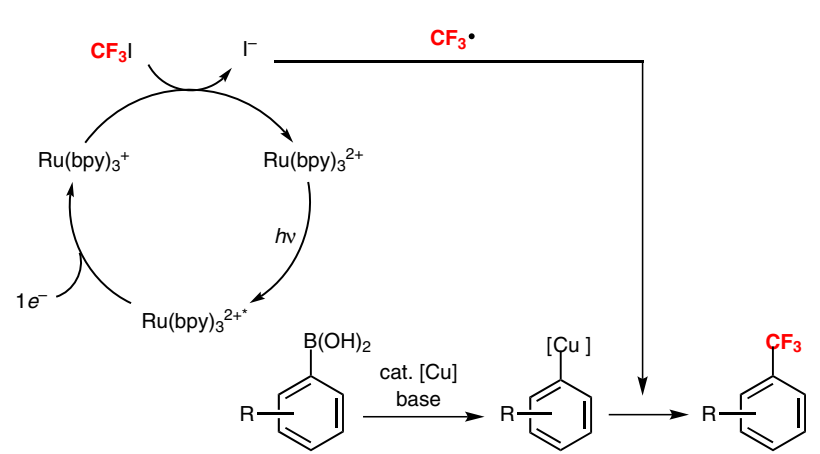

Scheme 20

Our investigations revealed that the reaction of $1,1^{\prime}$-biphenyl-4-ylboronic acid with $\mathrm{CF}_{3} \mathrm{I}$ in the presence of 20 $\mathrm{mol} \% \mathrm{Cu}(\mathrm{OAc}), 1 \mathrm{~mol} \% \mathrm{Ru}(\mathrm{bpy})_{3}{ }^{2+}$, and visible light (two $26 \mathrm{~W}$ household light bulbs) affords the trifluoromethylated product 4-(trifluoromethyl)-1,1'-biphenyl in high yield (Scheme 21). ${ }^{30}$ Importantly, the reaction proceeds in less than $5 \%$ yield when light, $\mathrm{Cu}$, or $\mathrm{Ru}$ are excluded from the reaction mixture, indicating that all three of these components are necessary for the major reaction pathway. Furthermore, less than $2 \%$ of competing $\mathrm{C}-\mathrm{H}$ trifluoromethylation of the substrate or product was observed, indicating that the relative rate of the $\mathrm{Cu}$-catalyzed process is faster than radical aromatic substitution.

Scheme 22 summarizes the scope of this transformation. As shown, this method is effective for the trifluorometh- ylation of a wide variety of aromatic and heteroaromatic boronic acid substrates bearing many common functional groups. Importantly, analogous perfluoroalkylation reactions of boronic acids can also be conducted under these conditions using inexpensive and readily available perfluoroalkyl iodide starting materials.

This work indicates that $\mathrm{Cu}$-catalyzed trifluoromethylation reactions involving $\mathrm{CF}_{3}$. intermediates can be viable and facile processes. We believe that it is possible (even likely) that many $\mathrm{Cu}$-catalyzed processes that were initially believed to involve $\mathrm{CF}_{3}{ }^{-}$or $\mathrm{CF}_{3}{ }^{+}$transfer actually involve radical intermediates. For example, several reports have shown that $\mathrm{Ag}$ salts serve as promoters for the $\mathrm{Cu}-$ catalyzed trifluoromethylation of aryl iodides. ${ }^{20 b, 31}$ The role of $\mathrm{Ag}$ has been proposed to involve mediating transmetalation of $\mathrm{CF}_{3}{ }^{-}$from $\mathrm{Si}$ (in $\mathrm{TMSCF}_{3}$ ) to $\mathrm{Cu}^{20 \mathrm{~b}}$ However, the current results (together with those detailed in Part 2 of this Account) suggest that the role of Ag may be to generate $\mathrm{CF}_{3}$ in these transformations. In addition, $\mathrm{CF}_{3}{ }^{+}$ reagents can potentially undergo $1 e^{-}$reduction to form $\mathrm{CF}_{3}{ }^{\circ}$, suggesting the possibility that $\mathrm{Cu}$-catalyzed reactions of $\mathrm{CF}_{3}{ }^{+}$reagents may also involve radical intermediates. ${ }^{28 c, 32}$

Our preliminary results also have implications for the future development of $\mathrm{Cu}$-catalyzed fluoroalkylation sequences. They suggest that combining aryl-Cu species (generated via transmetalation, $\mathrm{C}-\mathrm{H}$ activation, oxidative addition, etc) with perfluoroalkyl radicals (generated via

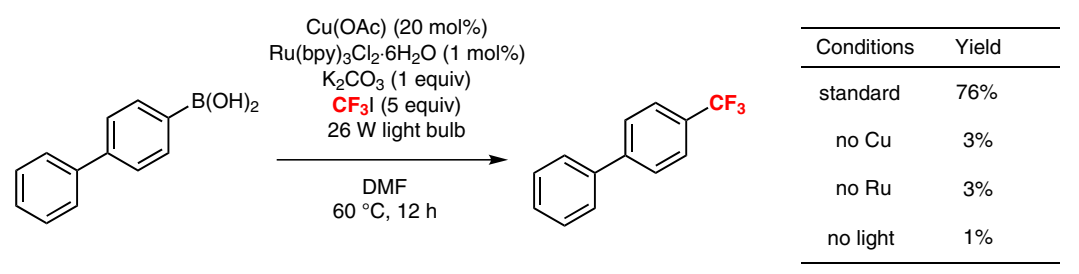

Scheme 21

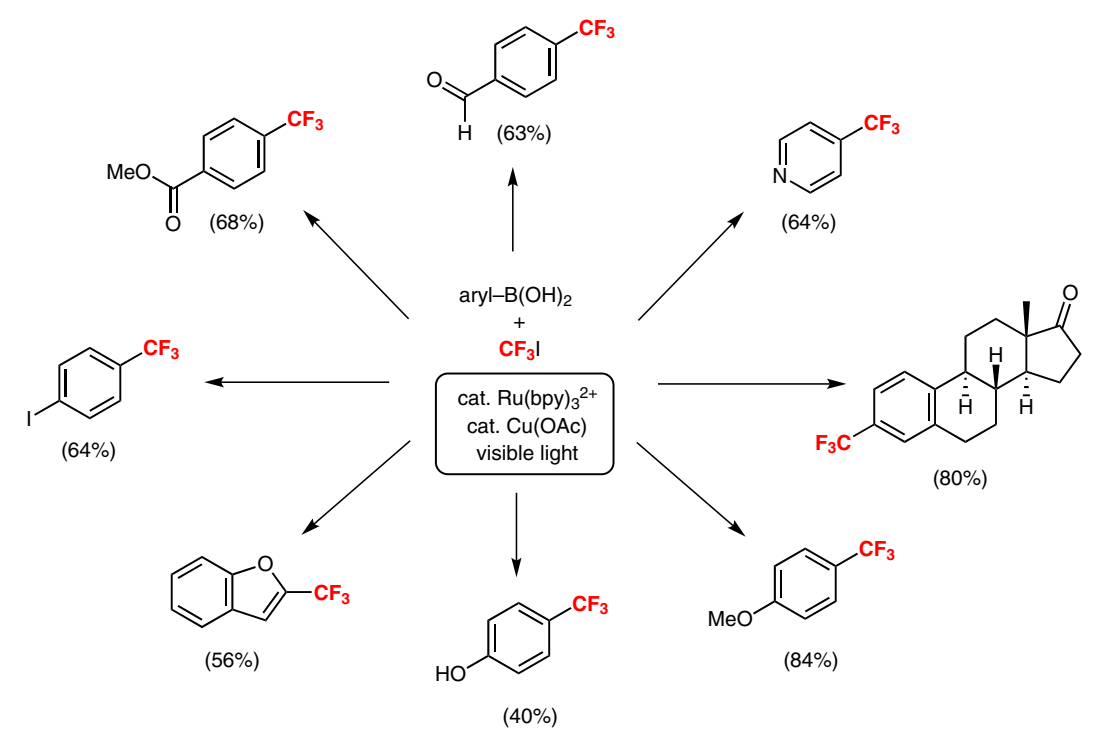

Scheme 22 Boronic acid trifluoromethylation reactions with $\mathrm{CF}_{3} \mathrm{I}$ 
various possible oxidative or reductive pathways) could prove to be broadly effective for the construction of new fluorinated molecules.

\section{$5 \quad$ Outlook}

Over the past five years, the field of aromatic trifluoromethylation has experienced an explosion of research activity. In parallel with our own efforts, numerous advances from other research groups around the world $^{1 f, 2,33}$ have dramatically expanded the organic chemists' toolbox for installing $\mathrm{CF}_{3}$ groups onto arenes and heteroarenes. As discussed above, our contributions to this area have particularly focused on discovering new oxidation states (e.g., $\mathrm{Pd}^{\mathrm{IV}}$ ), new metals (e.g., $\mathrm{Ag}$ ), and new reaction pathways (e.g., the combination of $\mathrm{Cu}$ and photogenerated $\mathrm{CF}_{3} \bullet$ ) for achieving aryl- $\mathrm{CF}_{3}$ coupling. Moving forward, we anticipate that detailed mechanistic studies of all of these transformations will provide valuable insights for the development of second-generation catalysts. Furthermore, the invention of novel pathways and reagents for these reactions should stimulate advances that further facilitate the assembly of trifluoromethylcontaining molecules.

\section{Acknowledgment}

This work was supported by grants from the NIH (GM073836) and NSF (CHE-1111563). We also acknowledge funding from NSF grant CHE-0840456 for X-ray instrumentation.

\section{References}

(1) (a) Schlosser, M. Angew. Chem. Int. Ed. 2006, 45, 5432. (b) Müller, K.; Faeh, C.; Diederich, F. Science 2007, 317, 1881. (c) Hagmann, W. K. J. Med. Chem. 2008, 51, 4359. (d) Kirk, K. L. Org. Process Res. Dev. 2008, 12, 305. (e) Purser, S.; Moore, P. R.; Swallow, S.; Gouverneur, V. Chem. Soc. Rev. 2008, 37, 320. (f) Tomashenko, O. A.; Grushin, V. V. Chem. Rev. 2011, 111, 4475. (g) Roy, S.; Gregg, B. T.; Gribble, G. W.; Le, V.-D. Tetrahedron 2011, 67, 2161.

(2) (a) Furuya, T.; Kamlet, A. S.; Ritter, T. Nature 2011, 473, 470. (b) Grushin, V. V. Acc. Chem. Res. 2010, 43, 160.

(3) Swarts, F. Bull. Acad. R. Belg. 1892, 24, 309.

(4) (a) Grushin, V. V.; Marshall, W. J. J. Am. Chem. Soc. 2006, 128, 12644. (b) Bakhmutov, V. I.; Bozoglian, F.; Gomez, K.; Gonzalez, G.; Grushin, V. V.; Macgregor, S. A.; Martin, E.; Miloserdov, F. M.; Novikov, M. A.; Panetier, J. A.; Romashov, L. V. Organometallics 2012, 31, 1315.

(5) (a) Dubinina, G. G.; Furutachi, H.; Vicic, D. A. J. Am. Chem. Soc. 2008, 130, 8600. (b) Dubinina, G. G.; Ogikubo, J.; Vicic, D. A. Organometallics 2008, 27, 6233.

(6) Oishi, M.; Kondo, H.; Amii, H. Chem. Commun. 2009, 1909.

(7) Cho, E. J.; Senecal, T. D.; Kinzel, T.; Zhang, Y.; Watson, D. A.; Buchwald, S. L. Science 2010, 328, 1679.

(8) (a) Hickman, A. J.; Sanford, M. S. Nature 2012, 484, 177. (b) Muniz, K. Angew. Chem. Int. Ed. 2009, 48, 9412. (c) Lyons, T.; Sanford, M. S. Chem. Rev. 2010, 110, 1147.
(9) (a) Ball, N. D.; Kampf, J. W.; Sanford, M. S. J. Am. Chem. Soc. 2010, 132, 2878. (b) Ball, N. D.; Gary, J. B.; Ye, Y.; Sanford, M. S. J. Am. Chem. Soc. 2011, 133, 7577.

(10) (a) Ball, N. D.; Sanford, M. S. J. Am. Chem. Soc. 2009, 131, 3796. (b) Ball, N. D.; Kampf, J. W.; Sanford, M. S. Dalton Trans. 2010, 632. (c) Canty, A. J. Acc. Chem. Res. 1992, 25, 83.

(11) (a) Racowski, J. M.; Gary, J. B.; Sanford, M. S. Angew. Chem. Int. Ed. 2012, 51, 3414. (b) Furuya, T.; Benitez, D.; Tkatchouk, E.; Strom, A. E.; Tang, P.; Goddard, W. A. I.; Ritter, T. J. Am. Chem. Soc. 2010, 132, 3793.

(12) Markies, B. A.; Canty, A. J.; Boersma, J.; van Koten, G. Organometallics 1994, 13, 2053.

(13) Mu, X.; Chen, S.; Zhen, X.; Liu, G. Chem. Eur. J. 2011, 17, 6039.

(14) Mu, X.; Wu, T.; Wang, H.-Y.; Guo, Y.-L.; Liu, G. J. Am. Chem. Soc. 2012, 134, 878 .

(15) Racowski, J. M.; Dick, A. R.; Sanford, M. S. J. Am. Chem. Soc. 2009, 131, 10974.

(16) (a) Powers, D. C.; Ritter, T. Acc. Chem. Res. 2012, 45, 840. (b) Canty, A. J. Dalton Trans. 2009, 10409.

(17) Ye, Y.; Ball, N. D.; Kampf, J. W.; Sanford, M. S. J. Am. Chem. Soc. 2010, 132, 14682.

(18) Wang, X.; Truesdale, L.; Yu, J.-Q. J. Am. Chem. Soc. 2010, 132,3648 .

(19) (a) Furuya, T.; Strom, A. E.; Ritter, T. J. Am. Chem. Soc. 2009, 131, 1662. (b) Furuya, T.; Ritter, T. Org. Lett. 2009, 11, 2860. (c) Tang, P.; Ritter, T. Tetrahedron 2011, 67, 4449 .

(20) (a) Tyrra, W. E.; Naumann, D. J. Fluorine Chem. 2004, 125, 823. (b) Weng, Z.; Lee, R.; Jia, W.; Yuan, Y.; Wang, W.; Feng, X.; Huang, K. W. Organometallics 2011, 30, 3229.

(21) Ye, Y.; Lee, S. H.; Sanford, M. S. Org. Lett. 2011, 13, 5464.

(22) (a) Wakselman, C.; Tordeux, M. J. Chem. Soc., Chem. Commun. 1987, 1701. (b) Akiyama, T.; Kato, K.; Kajitani, M.; Sakaguchi, Y.; Nakamura, J.; Hayashi, H.; Sugimori, A. Bull. Chem. Soc. Jpn. 1988, 61, 3531. (c) Sawada, H.; Nakayama, M. J. Fluorine Chem. 1990, 46, 423. (d) Langlois, B. R.; Laurent, E.; Roidot, M. Tetrahedron Lett. 1991, 32, 7525. (e) McClinton, M. A.; McClington, D. A. Tetrahedron 1992, 48, 6555. (f) Kamigata, N.; Ohtsuka, T.; Fukushima, T.; Yoshida, M.; Shimizu, T. J. Chem. Soc., Perkin Trans. 1 1994, 1339. (g) Kino, T.; Nagase, Y.; Ohtsuka, Y.; Yamamoto, K.; Uraguchi, D.; Tokuhisa, K.; Yamakawa, T. J. Fluorine Chem. 2010, 131, 98. (h) Loy, R. N.; Sanford, M. S. Org. Lett. 2011, 13, 2548.

(23) Ji, Y.; Brueckl, T.; Baxter, R. D.; Fujiwara, Y.; Seiple, I. B.; Su, S.; Blackmond, D. G.; Baran, P. S. Proc. Natl. Acad. Sci. U.S.A. 2011, 108, 14411.

(24) Nagib, D. A.; MacMillan, D. W. C. Nature 2011, 480, 224.

(25) Iqbal, N.; Choi, S.; Ko, E.; Cho, E. J. Tetrahedron Lett. 2012, 53, 2005.

(26) (a) Chu, L.; Qing, F. L. Org. Lett. 2010, 12, 5060. (b) Senecal, T. D.; Parsons, A. T.; Buchwald, S. L. J. Org. Chem. 2011, 76, 1174. (c) Khan, B. A.; Buba, A. E.; Gooßen, L. J. Chem. Eur. J. 2012, 18, 1577. (d) Jiang, X.; Chu, L.; Qing, F.-L. J. Org. Chem. 2012, 77, 1251.

(27) For an example of trifluoromethyl copper(I) reagent derived from $\mathrm{CF}_{3}^{-}$, see:Morimoto, H.; Tsubogo, T.; Litvinas, N. D.; Hartwig, J. F. Angew. Chem. Int. Ed. 2011, 50, 3793.

(28) (a) Liu, T.; Shen, Q. Org. Lett. 2011, 13, 2342. (b) Xu, J.; Luo, D. F.; Xiao, B.; Liu, J.; Gong, T. J.; Fu, Y.; Liu, L. Chem. Commun. 2011, 47, 4300. (c) Zhang, C. P.; Wang, Z. L.; Chen, Q. Y.; Zhang, C. T.; Gu, Y. C.; Xiao, J. C. Angew. Chem. Int. Ed. 2011, 50, 1896. 
(29) (a) Nagib, D. A.; Scott, M. E.; MacMillan, D. W. C. J. Am. Chem. Soc. 2009, 131, 10875. (b) Pham, P. V.; Nagib, D. A.; MacMillan, D. W. C. Angew. Chem. Int. Ed. 2011, 50, 6119

(30) Ye, Y.; Sanford, M. S. J. Am. Chem. Soc. 2012, 134, 9034.

(31) Li, Y. C. T.; Wang, H.; Zhang, R.; Jin, K.; Wang, X.; Duan, C. Synlett 2011, 1713.
(32) Zhang, C.-P.; Cai, J.; Zhou, C.-B.; Wang, X.-P.; Zheng, X.; Gu, Y.-C.; Xiao, J.-C. Chem. Commun. 2011, 47, 9516.

(33) Besset, T.; Schneider, C.; Cahard, D. Angew. Chem. Int. Ed. 2012, 51,5048 . 